\title{
TEOR DE HIDROXIPROLINA EM PELES DE FRANGO SUBMETIDAS À TRATAMENTO TÉRMICO
}

\author{
JOSÉ MAURÍCIO FRANÇA * \\ NINA WASZCZYNSKYJ **
}

\begin{abstract}
Extraiu-se colágeno da pele de coxa e sobrecoxa de frangos de corte mediante processamento térmico, quantificando-o na pele crua, na pele cozida e no resíduo de cozimento sob a forma de hidroxiprolina. Pele resfriada, oriunda da coxa e sobrecoxa de frangos de corte, de lotes mistos, de aves abatidas com idade entre 47 e 49 dias e peso vivo entre 2500 e $2600 \mathrm{~g}$ foi utilizada para o cozimento sob temperatura constante de $97,1 \stackrel{\circ}{ } \mathrm{C}$ por 30,60 e 120 minutos. Hidroxiprolina, proteína bruta e umidade foram determinadas quimicamente e os valores de colágeno obtidos por cálculo de conversão em relação a hidroxiprolina. A análise dos resultados evidenciou diferença entre os tratamentos. O cozimento exerceu efeito de solubilização da proteína estrutural da pele de frangos de corte, constatado pelos maiores teores de colágeno encontrados na pele cozida que na pele crua. O tempo ideal de cozimento para maior obtenção de proteína bruta no resíduo de cozimento foi de 60 minutos, devido a menor intensidade de desnaturação da proteína do resíduo. Os maiores teores de colágeno obtidos no resíduo de cozimento demonstram a sua característica hidrossolúvel, a viabilidade de sua extração e justifica esforços na recuperação e aplicação deste resíduo, minimizando o índice de dejetos no efluente.
\end{abstract}

PALAVRAS-CHAVE: COLÁGENO; PELES DE FRANGO; HIDROXIPROLINA.

\section{INTRODUÇÃO}

Colágeno é a proteína mais abundante nos organismos animais. Sendo a principal estrutura protéica do tecido conjuntivo, contém os aminoácidos glicina, prolina e hidroxiprolina em quantidades que representam 2/3 do seu conteúdo total. De acordo com HEDRICK et al. (1994) a hidroxiprolina apresenta-se em quantidades constantes no colágeno, representando 13 a $14 \%$ do seu conteúdo total. Não ocorre de modo

* Médico Veterinário, Mestre em Tecnologia Química pela Universidade Federal do Paraná. (e-mail: jose.franca@utp.br).

** Engenheira Química, Coordenadora do Curso de Pós-Graduação em Tecnologia Química, Universidade Federal do Paraná. (e-mail: ninawas@ufpr.br). 
significativo em outros tecidos animais, razão pela qual a quantificação da hidroxiprolina permite estimar o teor do colágeno nos tecidos, utilizandose rotineiramente para essa finalidade a técnica de leitura espectrofotométrica por colorimetria.

A pele oriunda da desossa de frangos de corte deve ser submetida a processamento térmico industrial para ser posteriormente utilizada na industrialização de produtos cárneos destinados ao consumo humano. ROSA, TREVISAN e TERRA (1997) constataram a existência de resíduo de cozimento de peles de frango, rico em proteínas, com características funcionais de interesse tecnológico para uso em produtos cárneos. HAMM (1977), citado por DEWREEDE e STEGEMANN (1982), afirmou que cozimento a partir de $60^{\circ} \mathrm{C}$ causa desnaturação do colágeno, caracterizada pela determinação da hidroxiprolina.

OSBURN e MANDIGO (1995) constataram que a incorporação de gel protéico ou colágeno pode aumentar o rendimento e melhorar a textura de produtos com baixos teores de gordura, agregando valor ao tecido conjuntivo recuperado de cozimento com potencial de retenção de água. LINDAU (2001) confirmou, recentemente, que o colágeno melhora os parâmetros comumente avaliados em produtos cárneos com relação à qualidade do produto final.

MARGGRANDER (1995) evidenciou a função de proteção coloidal da proteína colaginosa em quadros de ressecamento e quebras de cozimento em produtos cárneos.

O presente trabalho teve por objetivo extrair o colágeno da pele de coxa e sobrecoxa de frangos de corte mediante processamento térmico, assim como quantificá-lo, na pele crua, na pele cozida e no resíduo de cozimento sob a forma de hidroxiprolina. Este aminoácido que normalmente não se evidencia na maior parte das proteínas é encontrado quase que exclusivamente em colágeno animal.

\section{MATERIAL E MÉTODOS}

\subsection{MATERIAL}

Utilizou-se pele resfriada, oriunda da coxa e sobrecoxa de frangos de corte, de lotes mistos de aves abatidas com idade entre 47 e 49 dias e faixa de peso vivo entre 2500 e $2600 \mathrm{~g}$. 


\subsubsection{Reagentes e soluções}

Para a determinação química da hidroxiprolina foram utilizados reagentes grau analítico da Merck e água deionizada, sendo as soluções preparadas de acordo com as normas da AOAC (2000):

a) ácido sulfúrico $7 \mathrm{M}$;

b) solução tampão $\mathrm{pH} 6,0$;

c) solução oxidante com cloramina T reagente em $100 \mathrm{~mL}$ de solução tampão pH 6,0;

d) solução padrão de hidroxiprolina nas concentrações de $600 \mu \mathrm{g} /$ $\mathrm{mL}$ (denominada de solução estoque);

e) solução intermediária de $6 \mu \mathrm{g} / \mathrm{mL}$. Para as soluções de trabalho (curva de calibração) partiu-se da solução intermediária para preparar soluções contendo concentração de 0,6;1,2; 1,8 e $2,4 \mu \mathrm{g} / \mathrm{mL}$ de hidroxiprolina e;

f) solução de reagente de cor (4p-dimetilaminobenzaldeído em ácido perclórico 60\%, adicionado de álcool 2-propanol) preparada no dia do uso.

\subsection{MÉTODOS}

\subsubsection{Processo de separação e cozimento das peles}

Para a obtenção e preparo de cada amostra, carcaças de 20 frangos foram imersas em água com temperatura entre 2 e $3^{\circ} \mathrm{C}$ para resfriamento durante 50 minutos, seguido de gotejamento para remoção do excesso de água. As peles da coxa e sobrecoxa foram separadas dos músculos e dos ossos utilizando-se faca apropriada, com incisão circundando a base da articulação sacro-femoral, sem remover porções musculares.

As peles removidas foram lavadas em água destilada, cortadas em dimensões não superiores a $4 \times 5 \mathrm{~cm}$, homogeneizadas e mantidas sob refrigeração a $0 \pm 0,5^{\circ} \mathrm{C}$ por até 48 horas, para a realização das análises.

Para compor uma unidade de cozimento (amostra), $300 \mathrm{~g}$ da pele de frango previamente preparada foi colocada em béquer, acrescentando-se $300 \mathrm{~mL}$ de água deionizada a $20^{\circ} \mathrm{C} \pm 2^{\circ} \mathrm{C}$ com pH 7,6 (FRANÇA, 1997).

As amostras foram submetidas a cozimento durante 30,60 e 120 minutos sob fonte de calor mantida a $97,1^{\circ} \mathrm{C}$, visando simular processamento 
industrial. Após o final de cada tempo de cozimento, as amostras de pele cozida foram colocadas sobre malha de nylon para separar a parte líquida da sólida. O líquido drenado foi coletado em recipiente plástico, com tempo de perfusão de 5 minutos e mantido a $20^{\circ} \mathrm{C} \pm 2^{\circ} \mathrm{C}$ durante 12 a 36 horas. Neste período ocorreu a separação de fases, sendo possível constatar a presença da fase óleo no primeiro terço superior e da fase gel (colágeno) nas outras duas partes inferiores. A fase óleo foi então descartada por remoção com espátula e a fase gel utilizada para as análises.

As peles de frango cozidas, obtidas depois da drenagem, foram acondicionadas em sacos de polietileno e mantidas sob refrigeração a 0 $\pm 0,5^{\circ} \mathrm{C}$ durante no máximo 36 horas até a realização das análises físicoquímicas.

\subsubsection{Determinações físico-químicas}

Determinou-se a hidroxiprolina pelo método 990.26 da AOAC (2000), usando-se espectrofotômetro marca Micronal (modelo B295) e leitura a $558 \pm 2 \mathrm{~nm}$.

O valor do colágeno foi determinado pelos resultados analíticos da hidroxiprolina, também segundo a AOAC (2000), utilizando-se o seguinte fator de conversão: \% de colágeno $=8 \times \%$ de hidroxiprolina.

As determinações de proteína bruta e de umidade foram realizadas segundo os métodos analíticos oficiais para controle de produtos de origem animal (BRASIL, 1981).

\subsection{ANÁLISE ESTATÍSTICA}

O experimento foi realizado com delineamento inteiramente casualizado com três tratamentos e oito repetições. Os dados foram submetidos à análise de variância e a significância destes confirmada pelo Teste de Tukey.

\section{RESULTADOS E DISCUSSÃO}

A avaliação dos valores resultantes da análise química da hidroxiprolina (Tabela 1) evidenciou diferença entre os tratamentos na pele crua de coxa 
e sobrecoxa de frangos de corte pelo Teste de Tukey $(p<0,05)$.

TABELA 1- RESULTADOS DA DETERMINAÇÃO DE HIDROXIPROLINA ( $\mathrm{g} / 100 \mathrm{~g}$ EM BASE SECA) EM PELE CRUA E COZIDA E NO RESÍDUO EM 30, 60 E 120 MINUTOS DE COZIMENTO

\begin{tabular}{llll}
\hline TRATAMENTO & PELE CRUA & PELE COZIDA & RESIDUO \\
\hline COZIMENTO 30 $^{\prime}$ & $0,8150 \mathrm{a}$ & $0,7975 \mathrm{ab}$ & $3,8428 \mathrm{ab}$ \\
COZIMENTO 60 $^{\prime}$ & $0,8750 \mathrm{a}$ & $1,0950 \mathrm{a}$ & $6,0538 \mathrm{a}$ \\
COZIMENTO 120 $^{\prime}$ & $0,3775 \mathrm{~b}$ & $0,5150 \mathrm{~b}$ & $1,5000 \mathrm{~b}$ \\
\hline F(calculado) & $6,31^{*}$ & $4,61^{*}$ & $8,04^{* *}$ \\
Desvio Padrão & 0,3057 & 0,3823 & 2,2710 \\
Coeficiente de variação & 44,36 & 47,63 & 59,78 \\
\hline
\end{tabular}

Médias seguidas por letras iguais na mesma coluna não diferem estatisticamente entre si pelo Teste de Tukey $(p<0,05)$.

* Significância $p<0,05$ pelo Teste de $F$.

** Significância $p<0,01$ pelo Teste de F.

As peles cozidas por 30 e 60 minutos não apresentaram diferença significativa entre si, porém os resultados obtidos no cozimento de 120 minutos mostraram resultados inferiores aos menores tempos de cozimento.

Os teores de hidroxiprolina $(\mathrm{g} / 100 \mathrm{~g})$ nos resíduos dos cozimentos (Tabela 1) apresentaram diferença significativa entre os tratamentos pelo Teste de Tukey $(p<0,05)$.

Os valores de hidroxiprolina na pele cozida por 120 minutos apresentaramse baixos $(0,5150 \mathrm{~g} / 100 \mathrm{~g})$ em relação a 0,7975 g/100 g obtido em 30 minutos e $1,0950 \mathrm{~g} / 100 \mathrm{~g}$ para cozimento de 60 minutos. Tal fato evidencia que o calor excessivo de cozimento e o longo tempo de exposição das estruturas protéicas acarretam desnaturação irreversível. Estes resultados estão em consonância com as afirmações de McCRAE e PAUL (1974), SWINGLER e LAWRIE (1980), DEWREEDE e STEGEMANN (1982) e BONNET e KOPP (1992), que constataram o efeito do tratamento térmico na solubilização e desnaturação das proteínas estruturais.

O teor de hidroxiprolina no resíduo de cozimento apresentou-se maior que nas peles crua e cozida (Tabela 1), evidenciando a importância de que este resíduo seja recuperado para utilização das suas propriedades 
funcionais. O aquecimento do tecido conjuntivo ativa o colágeno, com solubilização parcial deste na forma de gel.

Os teores de colágeno em pele crua e cozida de coxa e sobrecoxa de frangos de corte apresentaram diferenças significativas entre os tratamentos. As amostras referentes aos cozimentos durante 30 e 60 minutos não apresentaram diferença significativa entre si, tanto para pele crua quanto para cozida. Já as amostras submetidas ao tratamento de 120 minutos de cozimento apresentaram diferença significativa pelo teste de Tukey $(p<0,05)$, embora se trate de amostras com as mesmas características de idade, nutrição, obtenção e preparo.

Os resultados da determinação do colágeno em peles crua e cozida apresentaram menores valores de desvio padrão, enquanto que no resíduo de cozimento obteve-se maior coeficiente de variação entre os resultados (Tabela 2).

Os teores de colágeno dos resíduos tratados durante 30, 60 e 120 minutos de cozimento foram superiores aos das peles cozidas (Tabela 2), devido a maior tempo para hidrólise e alto grau de evaporação do cozimento com aumento do teor de sólidos totais no resíduo.

\section{TABELA 2 - RESULTADOS DA DETERMINAÇÃO DO COLÁGENO (g/ $100 \mathrm{~g}$ EM BASE SECA) EM PELES CRUA E COZIDA E NO RESÍDUO EM 30, 60 E 120 MINUTOS DE COZIMENTO}

\begin{tabular}{llll}
\hline TRATAMENTO & PELE CRUA & PELE COZIDA & RESIDUO \\
\hline COZIMENTO 30 $^{\prime}$ & $6,5525 \mathrm{a}$ & $6,3888 \mathrm{ab}$ & $30,7738 \mathrm{ab}$ \\
COZIMENTO 60 $^{\prime}$ & $7,0238 \mathrm{a}$ & $8,7788 \mathrm{a}$ & $48,4475 \mathrm{a}$ \\
COZIMENTO 120 $^{\prime}$ & $3,0613 \mathrm{~b}$ & $4,1625 \mathrm{~b}$ & $12,0225 \mathrm{~b}$ \\
\hline F(calculado) & $6,27^{* *}$ & $4,57^{*}$ & $8,05^{* *}$ \\
Desvio Padrão & 2,4446 & 3,0549 & 18,1639 \\
Coeficiente de variação & 44,08 & 47,41 & 59,72 \\
\hline
\end{tabular}

Médias seguidas por letras iguais na mesma coluna não diferem estatisticamente entre si pelo Teste de Tukey $(p<0,05)$.

* Significância $\mathrm{p}<0,05$ pelo Teste de $\mathrm{F}$.

** Significância $p<0,01$ pelo Teste de $F$. 
O teor de colágeno nos resíduos de cozimento de 30 e 60 minutos apresentou valores superiores ao de 120 minutos em decorrência também de excessiva desnaturação da proteína, pelo longo tempo de exposição ao calor.

A determinação de proteína bruta em pele crua de coxa e sobrecoxa de frangos de corte não apresentou diferença significativa, pelo Teste de F.

Observou-se para os teores de proteína bruta do resíduo de cozimento (Tabela 3) diferença estatisticamente significativa entre os tratamentos. Como a média do tratamento de 120 minutos foi inferior aos demais, é possível presumir o efeito da excessiva ação do calor, acarretando a desnaturação protéica.

\section{TABELA 3 - RESULTADOS DE DETERMINAÇÃO DE PROTEÍNA BRUTA (g/100 g-BASE SECA), EM PELE CRUA E COZIDA E NO RESÍDUO EM 30, 60 E 120 MINUTOS DE COZIMENTO}

\begin{tabular}{llll}
\hline TRATAMENTO & PELE CRUA & PELE COZIDA & RESÍDUO \\
\hline COZIMENTO 30 & $13,1588 \mathrm{a}$ & $23,0513 \mathrm{~b}$ & $58,7025 \mathrm{a}$ \\
COZIMENTO 60 $^{\prime}$ & $13,7763 \mathrm{a}$ & $25,0988 \mathrm{ab}$ & $80,2962 \mathrm{a}$ \\
COZIMENTO 120 & $13,9538 \mathrm{a}$ & $26,9236 \mathrm{a}$ & $50,2013 \mathrm{~b}$ \\
\hline F(calculado) & $1,25 \mathrm{NS}$ & $5,02^{*}$ & $9,15^{\star *}$ \\
Desvio Padrão & 1,0571 & 2,4484 & 14,5099 \\
Coeficiente de variação & 7,76 & 9,78 & 23,01 \\
\hline
\end{tabular}

Médias seguidas por letras iguais na mesma coluna não diferem estatisticamente entre si pelo Teste de Tukey $(p<0,05)$.

* Significância $p<0,05$ pelo Teste de $F$.

** Significância $\mathrm{p}<0,01$ pelo Teste de $\mathrm{F}$.

NS - não significativo no Teste de Tukey.

A medida que se aumenta o tempo de cozimento, o teor de proteína da pele cozida também aumenta, havendo crescente remoção de umidade pelo calor, juntamente com material lipídico. Tal fato acarreta aumento no índice de sólidos no produto conforme BONNET e KOPP (1992) e OSBURN e MANDIGO (1995). Estes constataram que os teores de sólidos no resíduo de cozimento apresentam quantidade considerável de material conjuntivo protéico-estrutural na sua composição. 
Os valores resultantes da análise da umidade em pele crua de frangos de corte não demonstraram diferença significativa. Os valores de umidade da pele cozida nos diferentes tratamentos foram crescentes em relação aos maiores tempos de cozimento. Os dados apresentados na Tabela 4 mostram que maior tempo de cozimento aumenta a extração do material lipídico. Sugerem assim, relação direta e crescente entre o tempo de cozimento e a umidade $(51,63 \%$ para 30 minutos, $53,12 \%$ para 60 minutos e $55,31 \%$ para 120 minutos) na pele cozida de coxa e sobrecoxa de frangos de corte. Os resultados da umidade do resíduo de cozimento apresentados na Tabela 4, obtidos entre os cozimentos de 30 e 60 minutos, não demonstram diferença significativa.

\section{TABELA 4 - RESULTADOS DE DETERMINAÇÃO DO TEOR DE UMIDADE (\%) EM PELE CRUA E COZIDA E NO RESÍDUO EM 30, 60 E 120 MINUTOS DE COZIMENTO}

\begin{tabular}{llll}
\hline TRATAMENTO & PELE CRUA & PELE COZIDA & RESÍDUO \\
\hline COZIMENTO 30 ' & $40,2525 \mathrm{a}$ & $51,6363 \mathrm{~b}$ & $94,9700 \mathrm{a}$ \\
COZIMENTO 60 & $38,4550 \mathrm{a}$ & $53,1225 \mathrm{ab}$ & $94,6975 \mathrm{a}$ \\
COZIMENTO 120 ' & $40,6925 \mathrm{a}$ & $55,3125 \mathrm{a}$ & $85,2525 \mathrm{~b}$ \\
\hline F(calculado) & $3,52^{*}$ & $5,76^{*}$ & $76,02^{* *}$ \\
Desvio Padrão & 1,7880 & 2,1787 & 1,7950 \\
Coeficiente de variação & 4,49 & 4,08 & 1,96 \\
\hline
\end{tabular}

Médias seguidas por letras iguais na mesma coluna não diferem estatisticamente entre si pelo Teste de Tukey $(p<0,05)$.

* Significância $p<0,05$ pelo Teste de F.

** Significância $\mathrm{p}<0,01$ pelo Teste de F.

\section{CONCLUSÃO}

As conhecidas propriedades funcionais do colágeno em produtos à base de carne justificam a recuperação do resíduo de cozimento das peles de coxa e sobrecoxa de frangos de corte, uma vez que em base seca este resíduo apresentou maiores teores de colágeno que na pele crua ou na pele cozida. 
O cozimento exerce efeito de solubilização da proteína estrutural da pele de frangos de corte, constatado pelos maiores teores de colágeno na pele cozida, comparativamente à pele crua.

Os teores de umidade da pele cozida aumentaram conforme o aumento dos tempos de cozimento (entre 30 e 120 minutos).

Tempo de cozimento superior a 60 minutos em temperatura constante de $97,1^{\circ} \mathrm{C}$ acarreta menores teores de umidade no resíduo do cozimento e maiores teores de proteína bruta na pele cozida.

O tempo ideal de cozimento para maior obtenção da proteína bruta no resíduo foi de 60 minutos, devido menor intensidade de desnaturação da proteína.

\begin{abstract}
HIDROXIPROLIN CONTENT IN POULTRY SKIN SUBMITTED TO THERMAL TREATMENT

The collagen of poultry skin was extracted by thermal processing, and quantified in raw, cooked and in the residues of cooking in the hidroxiprolin form. Frozen skin from thigh and over-thigh poultry, of mixed lots, of poultry 47 and 49 days old and weighting between 2500 and $2600 \mathrm{~g}$ was utilized for cooking at constant temperature of $97.1^{\circ} \mathrm{C}$ for 30,60 and $120 \mathrm{~min}$. Hydroxiprolin, raw protein and humidity levels were determined chemically and collagen concentrations were calculated in function of hydroxiprolin levels. Statistical analysis of data showed differences between treatments. The cooking exerced effect of solubilization of structural protein of poultry skin. The ideal period of cooking for collagen extraction from the cooking residue was $60 \mathrm{~min}$ since the highest levels of raw protein were obtained at this time. The high levels of collagen in the residue demonstrate the solubility of the protein, the feasibility of its extraction and justifies any efforts in order to minimize its loss in waste water.
\end{abstract}

KEY WORDS: COLLAGEN; POULTRY SKIN; HIDROXIPROLIN.

\title{
REFERÊNCIAS
}

1 AOAC. Association of Official Agricultural Chemists. Official methods of analysis of AOAC international. $17^{\text {th }}$ ed. Gaithersburg, 2000. v. 2, Cap. 39, p.13-15.

2 BONNET, M.; KOPP, J. Préparation des échantillons pour le dosage et la caracterisation qualitative du collàgene musculaire. Viandres Prod. Carnés, v.13, n.3, p.87-91, mai./jun. 1992. 
3 DEWREEDE, I.; STEGEMANN, H. Trennung von muskelprotein, kollagen und elastin mit na-dodecylsulfat (SDS)- lösungen. Zeitschrift für Lebensmittel Untersuchung und Forschung, Brauschweig, v. 174, p. 200-207, 1982.

4 FRANÇA, J.M. Determinação do teor de colágeno em pele de frango submetida ao tratamento térmico. Curitiba, 1997. $89 \mathrm{f}$. Dissertação (Mestrado em Tecnologia Química), Setor de Tecnologia, Universidade Federal do Paraná.

5 HEDRICK, H.B. et al. Principles of meat science. $3^{\text {th }}$ ed. Dubuque: Kendall Hunt, 1994. 355 p.

6 BRASIL. Ministério da Agricultura. Laboratório Nacional de Referência Animal (LANARA). Métodos analíticos oficiais para controle de produtos de origem animal e seus ingredientes. Brasília, 1981. v. 2 - Métodos físico-químicos.

7 LINDAU, E. Hilfestellung bei neuentwicklungen. Fleischwirtschaft, Frankfurt am Main, v. 6, p.30-33, 2001.

8 MARGGRANDER, K. Kollagene proteine als hilfstoffe zur verbesserung der teschnologischen und sensorischen eigenschaften von fleischerzeugnissen und fertiggerichten. Fleischwirtschaft, Frankfurt, v. 75, n.11, p. 1286-1287, 1995.

9 McCRAE, S.E.; PAUL, P.C. Rate of heating as affects the solubilization of beef muscle collagen. Journal of Food Science, v. 39, p. 18-21, 1974.

11 ROSA, C.S., TREVISAN, A.C.C., TERRA, N.N. Utilização da pele de frango em produtos emulsionados. In: SIMPÓSIO LATINO AMERICANO DE CIÊNCIA DE ALIMENTOS, 2., 1997, Campinas. Anais... Campinas: Unicamp, 1997. p. 67.

12 OSBURN, W.N.; MANDIGO, R.W. Gelatinizated recovered beef connective tissue protein gels as potential water binders. Lincoln, NE: University of Nebraska, 1995.

13 SWINGLER, G.R.S.; LAWRIE, R. A. Improved protein recovery from some meat industry by-products. Meat Science, Loughborough, v.3, p. 63-73, England, 1980. 